\title{
MODERN TRENDS IN DESIGNING AND SELECTING THE MACHINE/EQUIPMENT FOR DEEP SOIL TILLAGE
}

\author{
Vladutoiu Laurentiu ${ }^{1}$, Petru Cardei ${ }^{1}$, Valentin Vladut ${ }^{1}$, Fechete Lucian $^{2}$ \\ ${ }^{1}$ INMA Bucharest, Romania; ${ }^{2}$ Technical University of Cluj-Napoca, Romania \\ laurentiuvladutoiu82@gmail.com,petru_cardei@yahoo.com
}

\begin{abstract}
The article proposes a method for extracting the main characteristics of the machines for deep soil tillage using as sources only leaflets and public technical documentation provided by manufacturers. The method consists in a statistical analysis of quantitative numerical characteristics provided by manufacturers and the development of original calculation criteria (formulas) in order to rank machines performances. Methodology results consist in ranking performances of the machines that can be used for two main purposes: selection, by consultants or potential users, of machines or equipment appropriate to the geographical and climate characteristics of the area where the target farm is located; and highest level design of equipment and machines for deep soil tillage taking into account the most advanced trends in the field, the useful directive for designers services, firms of design and manufacturing for the equipment destined for deep processing of soil. The method is general and can be applied to all types of agricultural machinery, mainly for the 2 benefits mentioned above: efficient selections for users and highest level design for manufacturers.
\end{abstract}

Keywords: deep tillage, data basis, statistical analysis, ranking, consultant, trends.

\section{Introduction}

Soil compaction is one of the most important issues in agriculture, respectively in crop production, through settlement and destruction of soil structure, and is often closely linked to intensive production. It is estimated that $65 \%$ of agricultural land in Eastern Europe is compacted, which leads to yield losses between $15 \%$ and $35 \%$, according to George Stanson, business manager for Romania, Bulgaria, Croatia and Serbia for Case IH \& Steyr [1].

Deep loosening aims to achieve a radical change of soil structure in the compacted, settled and impermeable layer, thus increasing the capacity of water storage, creating conditions for normal aeration and heating of soil and for the activation of biological processes in the soil [2].

Deep loosening increases the volume of soil pores, the lacunar space that allows quick drainage of water and accelerates the flow of surface water, which helps the soil to dry faster in the spring.

Also, by loosening of the compacted layers of the arable layer, favourable conditions are created for the penetration of plant roots, increasing their feeding area and thus increasing their resistance to drought.

During deep loosening, due to the stress, in the mass of soil layers it occurs the cracking and partial displacement, which propagates in an area that depends on the depth at which the ploughshare operates, the width of ploughshare and the angle at which it occurs the cracking and displacement of soil layers under the action of the ploughshare, the working speed etc.

It has been established that the efficiency of loosening is obvious in soils where the compacted layers have the following characteristics [2]:

- bulk density greater than $1.40 \mathrm{~g} \cdot \mathrm{cm}^{-3}$;

- aeration porosity below $20 \%$;

- penetration resistance greater than $200 \mathrm{daN} \cdot \mathrm{cm}^{-2}$.

Soil improvement by deep loosening is part of a set of measures comprising the following stages:

- mobilisation of compacted layers of soil;

- stabilization of soil loosening;

- maintenance of loosened soils.

\section{Materials and methods}

In order to achieve some improvements or even optimisation (actions of scarifier type agricultural machinery, which would lead to increased competitiveness of machines and equipment for deep tillage of soil), it is useful and necessary to make a review of the performance of agricultural machinery and equipment for deep soil tillage, both in Romania and abroad. Knowledge of this type of machines and 
equipment and some of their characteristics is facilitated by the development and use of a database. Such database is not only a comparison instrument but also an inspirational one for achieving project objectives.

Therefore, a database was created with inputs coming from the public domain. The information comes from the websites of agricultural machinery manufacturers, from advertising leaflets and propaganda materials found in various publications (for example, specialty journals). Some of the used sources are found in references [3-15].

Thus, structure of the database consists of information such as: name of the equipment; producer name; minimum necessary traction power, in HP; maximum necessary allowed for power traction, in HP; working width, in m; minimum working depth, in cm; maximum working depth, in cm; number of active parts; distance between the parts, in $\mathrm{m}$; productivity in ha/h; overall dimensions, in $\mathrm{m}$; mass, in kg; fuel consumption; working speed; annexes, etc. The database was created in Microsoft Office Excel application, following the diagram model in Fig. 1.

INPUT DATA

\section{OUTPUT DATA}

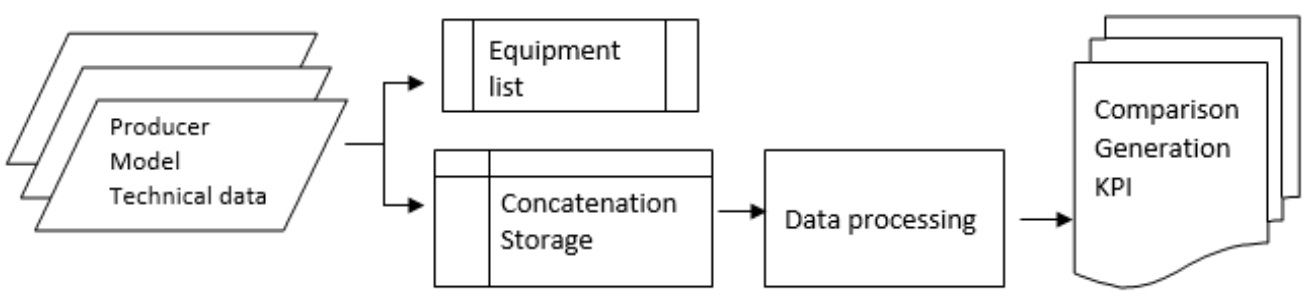

Fig. 1. Flow chart of the structure of created database

Except for those mentioned before, as shown in Figure 1, the database contains several performance estimators. They are used to enable the comparative analysis of selected products. It must be taken into account that not all the data is supplied by producers in the studied materials, nor they were interested in providing some of the missing data. Moreover, to provide data such as productivity or fuel consumption, are important the external conditions in which the experimental determinations are made: resistance to deformation and soil structure, soil moisture, quality of materials used (tires, tracks, fuel etc.).

\section{E1) Specific mass of the unit of tilled surface (MsuSP)}

This estimator shows the report between the equipment mass and the product between its working width and working depth.

This performance estimator is in fact only an indicator of the material consumption in construction of the structure, in order to carry out the established soil works and at the quality required (that we cannot quantify in the absence of experimental data).

To give the reader a quicker and easier to understand image of the avriation of this estimator on the set of equipment included in the database, we recommend the reader to go through the text in parallel with the database (http://www.subsoil.utcluj.ro/ Baza_date.html).

The machines, for which some of the data necessary to calculate this estimator are missing, are represented on the graph in 0 point. This estimator, if the equipment has no parts attached, or the mass doesn't include the attached parts, is significant for the consumption of material necessary to give the structure the strength needed to perform the work on the required width and depth. The database allows comparing, under these terms, the designed products with those available on the market.

In terms of MsuSP indicator, remarcable performances in this field have been achieved by companies FONTANA S.R.L, EVAK S.A. and F.LLI MARINELLI S.R.L and at the other end are those produced by MASCHIO-GASPARDO ROMANIA S.R.L. Comparatively, the reduced values of this indicator show the possibility of existance, from a structural point of view, of an optimized contruction or, at the extreme, of a fragile construction with limited functionality in difficult working conditions. On the other hand, high values of this indicator show the use of an increased safety coefficient when producing the machines, the use of materials with low mechanical resistance and high density or, to the extreme, an inefficient project (design) from the structural point of view. 


\section{E2) Working width specific to a working part ( $\mathrm{Lls} \mathrm{OL}$ )}

This estimator is defined as the ratio between the machine (equipment) working width and its number of active parts.

This estimator appeared as a first response to an older question regarding the version that the resistance of processed soil is lower: working with more parts, each with its own smaller width or working with fewer working parts, each with a larger working width, obviously, for the same working width.

LlsOL estimator is calculated in the database on the sheet called CHARACTERISTICS. For an easier understanding of the utility of this estimator and its use, graphical representation similar to that of the estimator MsuSP, we recommend the reader to go through the text in parallel with the database (http://www.subsoil.utcluj.ro/Baza_date.html). The machines that have at least one of the three data required in the calculation of this estimator are represented on the graph in 0 point.

Making a comparison, it is noticed that the biggest ratio between the working width of the equipment (machine or equipment) and the number of active parts is found for companies Kverneland Group UK Ltd and EVAK S.A while at the other end are those produced by John Deere.

E3) Specific power necessary for processing the unit of soil surface (PsnPuss)

The estimator PsnPuss is defined as the ratio between the necessary power (minimum, respectively maximum) for driving the equipment and the multiplication of working width and working depth.

The calculation of this estimator is made in the first database sheet. We recommend the reader to go through the text in parallel with the database (http://www.subsoil.utcluj.ro/Baza_date.html).

This estimator expresses the required power specific to a square meter of field profile processed by the machine, in the rectangular part of flat surface perpendicular to the direction of movement of the aggregate, having the length equal to the working width of the machine and the width equal to the working depth. Also a graphical representation of the minimum and maximum power required during operation for the machines from the database will be made. We recommend the reader to go through the text in parallel with the database (http://www.subsoil.utcluj.ro/Baza_date.html).

In terms of this indicator, we can notice that the lowest specific power necessary for processing the unit of soil surface was found for MA-AG S.r.l. and EVAK S.A, while the highest specific power is found for ALPEGO S.P.A and MASCHIO-GASPARDO ROMANIA S.R.L.

\section{E4) Active working surface per working part (SalOL)}

The estimator called working active surface per working part (SalOL) is defined as the report between the surface currently processed by working parts (rectangle surface with length equal to the machine working width and the width equal to the machine working depth, perpendicular to the direction of aggregate advancing) and the number of the same equipment working parts. The variation of this estimator based on the elements of this database will be represented graphically in the spreadsheet. We recommend the reader to go through the text in parallel with the database (http://www.subsoil.utcluj.ro/Baza_date.html). This estimator is not correlated with the machine mass (it can be compared the can be compared graphical representation of this estimator with the graphical representation of the machines included in this database).

Making a comparison, it is found that the smallest working parts are used by company Legmas S.A. while the biggest are used by John Deere.

\section{Results and discussion}

Analysing the 119 machines and equipment included so far in the database, we can draw several conclusions:

First, several immediate characteristics are illustrative:

- The mass of the structures included in the database ranges between $380 \mathrm{~kg}$ (scarifier RY62 180/5 EVAK produced by EBAK) and $9900 \mathrm{~kg}$ (scarifier DIBLO 700/1 produced by Maschio Gaspardo); the average mass of a machine in this database is $1845 \mathrm{~kg}$ (ARTECOM product is part of the category of light machine, below the average mass; Figure 2 shows that most equipment have a mass ranging between 1000 and $2000 \mathrm{~kg}$ ). 


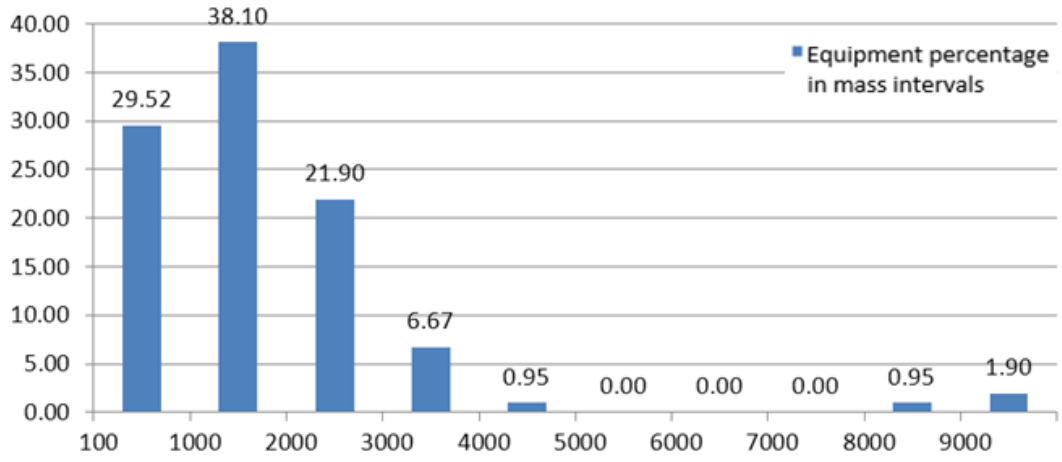

Fig. 2. Percentage of the equipment in the database, found in mass boxes of $1000 \mathrm{~kg}$ (except for the lowest one)

- The smallest working width of a machine included in this database is $1.3 \mathrm{~m}$ (scarifier PINOCCHIO 130/3 produced by Maschio Gaspardo), while the maximum working width is 7 $\mathrm{m}$ (the machine with the biggest mass, the scarifier DIBLO 700/1 of Maschio Gaspardo); the average working width in this database is $3 \mathrm{~m}$.

From Figure 3 it can be seen that about half of the machines in the database have widths ranging between 2 and $3 \mathrm{~m}$. Hence, these machines have the highest demand on the market, so it is inferred that working widths between 2 and $5 \mathrm{~m}$ would cover nearly all market demands.

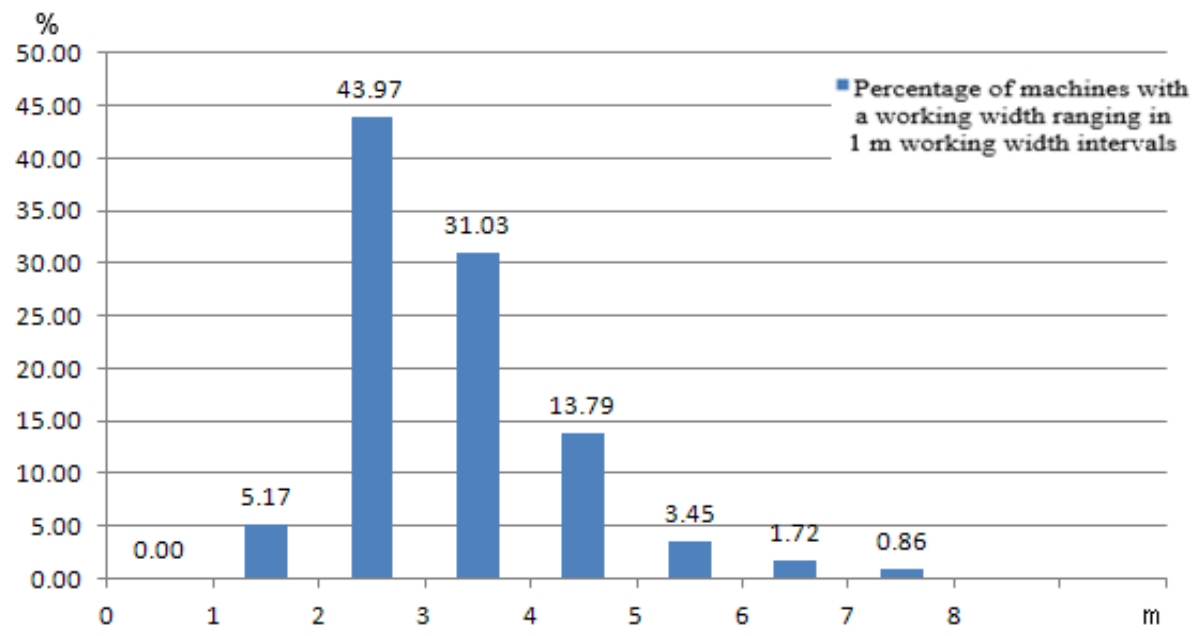

Fig. 3. Distribution of machines in the database in boxes of $\mathbf{1} \mathbf{~ m}$ working width

- The maximum working depth has values between $25 \mathrm{~cm}$ (Chisel PC7 and PC15, produced by LEGMAS) and $90 \mathrm{~cm}$ (RP M9, P5 and P7 scarifiers produced by Bigham) and is presented in Figure 4; the average value of the working depth for the machines in this database is $56 \mathrm{~cm}$.

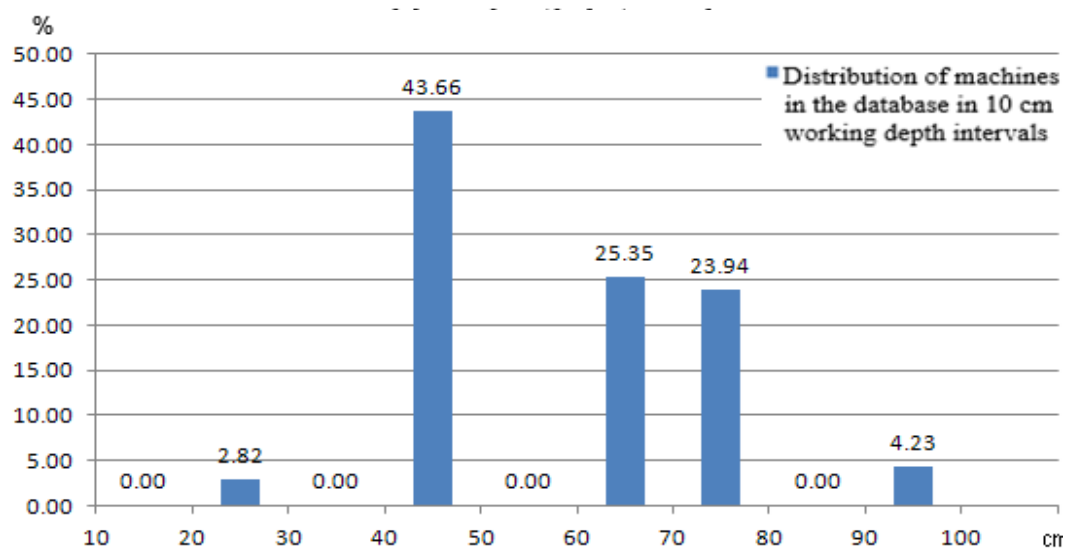

Fig. 4. Distribution of machines in the database bt their working width 
- The number of working parts ranges between 3 (scarifier PINOCCHIO 130/3, Maschio Gaspardo) and 17 (scarifier CV 17 HD FX Flingk, company Kverneland Group UK Ltd), illustrated in Figure 5; the average number of working parts of the machines in this database is 7.

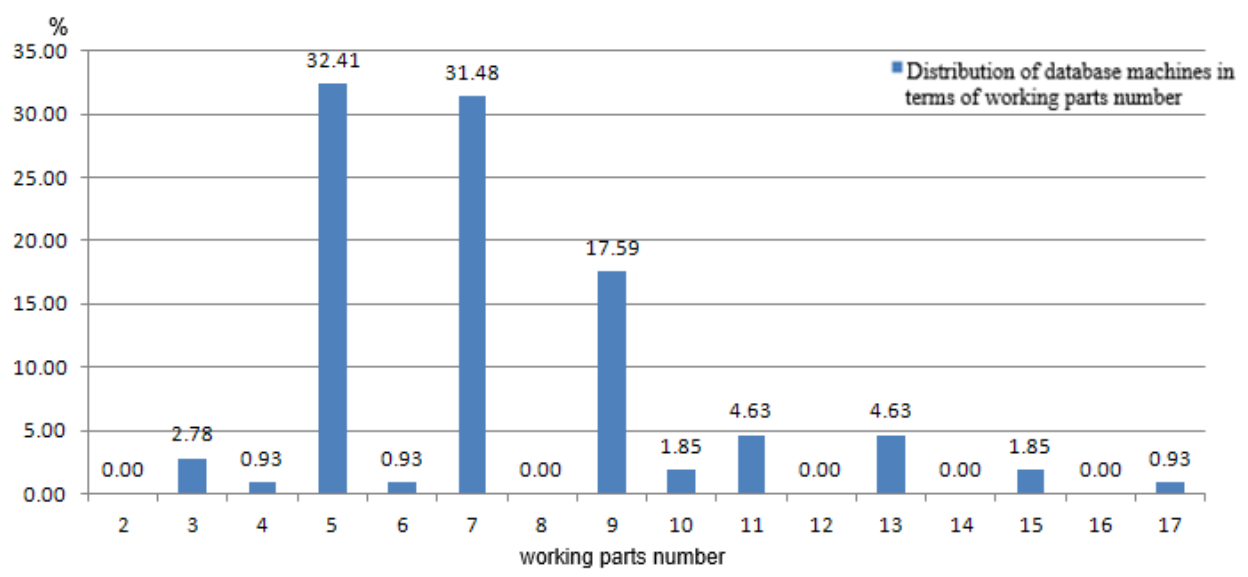

Fig. 5. Distribution of machines in the database by the number of working parts

Figure 6 shows that the producers included in the database prefer a density of working parts of about 2 - 2.5 working parts per meter.

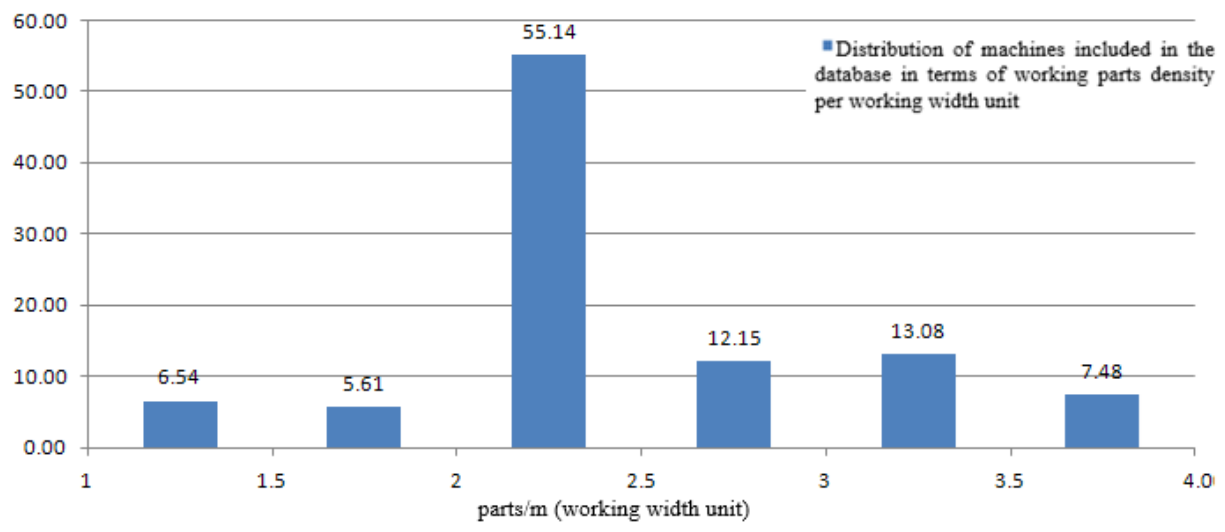

Fig. 6. Distribution of machines in the database by the density of working parts per meter of working width

\section{Conclusions}

1. The mass and working width of machines are highly correlated; the correlation value of these characteristics is 0.779 .

2. The working width and number of working parts of the machines in the database are also highly correlated characteristics, with correlation value of 0.666 .

3. The mass of machines and the number of working parts are relatively well correlated, having a correlation value of 0.494 .

4. The mass and maximum working depth, as well as working depth and the number of working parts, are lowly correlated or anticorrelated.

5. The maximum power required during operation for the machines included in this database is highly correlated with the working width (correlation coefficient 0.774 ), almost as high as the mass of machine (correlation coefficient 0.737 ) and lower (but significantly) correlated with the working depth (correlation coefficient 0.244).

6. The ratio between working depth and working width of a working part can be viewed using the graphic representations in the spreadsheet "Part width-depth relation".

7. It can be seen that some of the machines included in the database have the load-bearing structure made of beams (bars), while another part have the load-bearing structure made of beams (bars) and plates. The latter are more recent machines. However, load-bearing structure made solely of 
beams hasn't been abandoned. Elementary statistics indicate that only $37 \%$ of the machines included in the database have plates in the load-bearing structure.

\section{Acknowledgements}

This work was supported by Grant of the Romanian National Authority for Scientific Research, CNCS, UEFISCDI, PN-III-P2-2.1-BG-2016, Project number: 78BG/2016, SC Artecom SRL upgraded competences through deep soil tillage machinery optimization.

\section{References}

1. Tasarea solului - fenomenul care scade producțiile cu până la $35 \%$. Ce soluții au fermierii pentru "a sparge" hardpan-ul? (Tillage - the phenomenon that reduces production by up to $35 \%$. What are the farmers' solutions for "breaking" the hardpan?) [online][17.11.2017] Available at: http://agrointel.ro/51823/tasarea-solului-fenomenul-care-scade-productiile-cu-pana-la-35-cesolutii-au-fermierii-pentru-a-sparge-hardpan-ul/. (In Romanian)

2. Constantin N. et alii Creating and promoting a TE for deep loosening of poor soils, in the same time with applying nutrients, destined to high power tractors, Research report, contract 15/19.09.2007.

3. MAS 5 product page [online][17.11.2017] Available at: http://www.mecanicaceahlau.ro/productdetail/mas-5/. (In Romanian)

4. Scarificator Agricol cu Nivelator (Farm Scarifier with Leveling) [online][17.11.2017] Available at: http://www.agrometejea.ro/produs.php/ro/scarificator-agricol-usor/49. (In Romanian)

5. Plugul Cizel PC7 - Legmas S.A.Legmas S.A. product page [online][17.11.2017] Available at: http://www.legmas.ro/plugul-cizel-pc7/.

6. ATTILA HYDRO product page [online][17.11.2017] Available at: http://www.maschio.com/catalog/product/attila-idropneumatico/ro_RO. (In Romanian)

7. EVAK SA homepage. [online][17.11.2017] Available at: http://www.ebak.gr/index.php/ro/.

8. Series RP product page. [online][17.11.2017] Available at: http://www.fontanasrl.com/levellers/ripper-RP.htm.

9. 06 - Estirpatori pesanti - Ripuntatori dissodatori - RIPUNTATORI product page [online][17.11.2017] Available at: http://www.ma-ag.com/2010/10/ripuntatori/. (In Romanian)

10. PARAGRUBBER ECO 3000 product page [online][17.11.2017] Available at: http://www.kongskilde.com/Agriculture/Soil/Sub\%20Soilers/Sub\%20Soilers/PARAGRUBBER\% 20ECO\%203000. (In Romanian)

11. Subsoiler Kverneland CLI product page [online][17.11.2017] Available at: http://uk.kverneland.com/Kverneland-Soil-Equipment/Cultivators/Subsoilers/SubsoilerKverneland-CLI.

12. Fixed tine cultivator (Heavy Duty) [online][17.11.2017] Available at: http://flingk.com/products/141/tillage-technique/fixed-tine-cultivator-heavy-duty.

13. Marinelli - Land preparations homepage [online][17.11.2017] Available at: http://samagri.co.za/land-preparation/marinelli_land_preparations/.

14. 2100 Minimum Till-Ripper product page [online][17.11.2017] Available at: https://www.deere.com/en_US/products/equipment/tillage_equipment/primary_tillage/2100_mini mum_till_ripper/2100_minimum_till_ripper.page.

15. Alpego CRAKER KE7 - 300 [online][17.11.2017] Available at: http://www.mewi.ro/ro/produs/alpego-craker-ke7-300. (In Romanian) 